\title{
DESREGULACIÓN, ESTADO SOCIAL Y PROCESO DE GLOBALIZACIÓN*
}

\author{
Gema Marcilla Córdoba \\ Universidad de Castilla-La Mancha
}

\begin{abstract}
RESUMEN. Uno de los factores más relevantes en la crisis de la "estatalidad" del Derecho es el creciente protagonismo de grupos y corporaciones, sobre todo económicos, en los procesos de creación de normas. Se trata de manifestaciones de pluralismo jurídico, que resultan de especial interés para explicar el fenómeno de la desregulación. Al contrario de lo que la expresión puede sugerir, la desregulación no equivale a la anomia, sino que se identifica con el desplazamiento de normas intervencionistas, propias del Estado social, por otras cuya función se limita a asegurar la autonomía privada y la libre competencia entre sujetos que operan en el mercado. La desregulación suele justificarse en razones de eficiencia del mercado, pero también en razones de mayor legitimidad de las instancias públicas. Si bien la desregulación está cobrando importancia en el ámbito del Derecho estatal, es seguramente en el plano transnacional en el que más se advierte su presencia. Es más, cabría decir que la desregulación es la técnica normativa más característica de la sociedad global (piénsese en la nueva lex mercatoria): los agentes económicos que operan a escala global necesitan normas uniformes, adecuadas a los avances científicos y tecnológicos,
\end{abstract}

Abstract. One of the most important factors in the crisis of production of law by the state public powers is, together with the supra and infra-production of legal norms phenomena, the increasing protagonism of groups and corporations, mainly economic, in the processes of creation of norms. It can be presented as an example of legal pluralism, which is of especial interest when explaining the "deregulation" phenomenon. In spite of what can be suggested by this expression, deregulation is not equivalent to anomia (the absence of rules), rather it is considered as the displacement of interventionist norms, existing in the Welfare State, by other norms whose function is to guarantee private autonomy and free competition between those who operate in the market. Deregulation is usually justified in terms of market efficiency, but also in terms of greater legitimacy of public bodies. Although deregulation is becoming increasingly important in the sphere of state law, it is in the international field where its presence is undoubtedly most noticeable. Furthermore, it could be said that deregulation is the paradigmatic normative technique found in global society (for instance, the new lex mercatoria): the economic agents who operate on a

${ }^{*}$ El presente trabajo ha sido realizado en el marco del proyecto PAI-05-055, financiado por la Junta de Comunidades de Castilla-La Mancha. 
que doten de seguridad y protejan frente a la delincuencia a las transacciones comerciales, y muy especialmente necesitan normas que no pongan trabas al mercado. Éste es precisamente el tipo de Derecho que propicia la desregulación. global scale need uniform norms which should be in accordance with scientific and technological breakthroughs, norms which should provide legal certainty and protect commercial transactions from delinquency, and they especially need norms which do not obstruct the market. This is precisely the type of law which results from deregulation.

\section{I) Introducción}

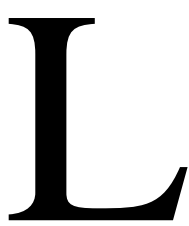

a ley estatal representa el monopolio del poder de creación del Derecho en una instancia dotada de legitimidad pública. Precisamente por ello la historia de esta categoría jurídica discurre en paralelo a la de la formación del Estado Moderno: durante la Edad Media la ley se ve obligada a convivir con otras fuentes del Derecho, hasta convertirse en el principal instrumento jurídico de los procesos revolucionarios que logran poner fin al Antiguo Régimen. La ley se convierte así en la fuente del Derecho por excelencia del decimonónico Estado liberal y, con las peculiaridades propias del constitucionalismo, conserva una posición preeminente en los ordenamientos jurídicos contemporáneos.

Sin embargo, esta descripción tradicional y habitual de la importancia de la ley estatal resulta cada vez menos representativa de la realidad jurídica. La “estatalidad” de las fuentes del Derecho es un rasgo en crisis, y así lo evidencian los diferentes procesos de descentralización normativa, como el que tiene lugar con la integración de ordenamientos jurídicos de ámbito territorial superior al Estado, o en virtud de la convivencia del Derecho estatal central con el producido por entes autonómicos o regionales de carácter infraestatal.

Junto a los factores mencionados, una de las causas más significativas del retroceso de la estatalidad del Derecho es el creciente protagonismo normativo de grupos y corporaciones, sobre todo de tipo económico, integrantes de la sociedad civil. Estas manifestaciones de pluralismo jurídico dentro del Estado resultan de especial interés para explicar el fenómeno de la llamada “desregulación”, pues, al contrario de lo que la expresión puede sugerir, no equivale a la anomia, sino que se identifica con el desplazamiento de normas intervencionistas por otras limitadas a asegurar la autonomía privada y la libre competencia entre sujetos que operan en el mercado. En 
efecto, grupos económicos, como las grandes empresas multinacionales, protagonizan uno de los procesos más significativos de adelgazamiento del poder normativo estatal. Su poder de influencia normativa se pone de manifiesto cuando las leyes son permeables a los intereses de estos actores económicos, pero también cuando las propias instituciones públicas consienten, propician o se ven obligados a aceptar procesos de desregulación. La desregulación suele justificarse en razones de eficiencia del mercado, pero también en razones de mayor legitimidad de las decisiones públicas, e incluso se sostiene que esta forma de producción normativa constituye una solución al desbordamiento del Estado asistencial, favoreciendo el funcionamiento y la mejor prestación de servicios a los ciudadanos.

La desregulación, pues, está cobrando importancia en el ámbito del Derecho estatal, pero seguramente los ejemplos más claros de desregulación se advierten en el plano transnacional, hasta el punto de que cabría decir que la desregulación es la técnica normativa más característica de la sociedad global (piénsese en la nueva lex mercatoria): los agentes económicos que operan a escala global necesitan normas uniformes, adecuadas a los avances científicos y tecnológicos, que doten de seguridad y protejan frente a la delincuencia a las transacciones comerciales, y muy especialmente necesitan normas que no pongan trabas al mercado. Éste es precisamente el tipo de Derecho que propicia la desregulación.

Sin duda, la desregulación ofrece interesantes ventajas para los sujetos económicos privados, pero esta emergente forma de producción del Derecho encierra también aspectos discutibles, siendo tal vez el más evidente el debilitamiento de la participación y de la representación en condiciones de igualdad de los intereses de los posibles afectados por estas normas de gestación, desarrollo y aplicación privadas. En el plano transnacional, el auge de la desregulación contrasta con un vacío de Derecho público internacional, que muchas opiniones autorizadas consideran que pone en riesgo aspectos básicos de la convivencia mundial, en la medida en que la ausencia o la ineficacia de las normas de Derecho internacional público, unidas al poder normativo de los sujetos económicos privados, aparte de dejar sin respuesta urgentes problemas globales, pone en auténtico peligro la propia paz y seguridad mundial ${ }^{1}$.

\footnotetext{
${ }^{1}$ La Declaración de Granada sobre la globalización resalta que "la globalización es un fenómeno nuevo que ha colocado otra vez a la sociedad internacional en una especie de estado de naturaleza que necesita ser sometido a regulación”, Jürgen Habermas, David Held y Will Kymlicka, Diario El País, “Opinión”, 06 de Junio de 2005. Firman asimismo esta declaración Francisco J. Laporta, Nicolás López Calera, Manuel Atienza, William Twining, Robert Alexy, Luigi Ferrajoli, Elías Díaz, Boaventura de Sousa Santos, Neil Maccormick, Paolo Comanducci, Zhan Wenxian, Uma Narayan, Larry May y otros 200 participantes en el XXII Congreso
} 


\section{II) La crisis de la estatalidad del derecho: los fenómenos de supra- e infraestatalidad normativa y la emergencia de los grupos económicos y sociales}

El monopolio del poder de creación del Derecho por el Estado padece hoy una incuestionable crisis, que, en opinión de algunos autores, es además una crisis irreversible ${ }^{2}$. El retroceso de la estatalidad del Derecho se advierte, como es evidente, en relación con el modelo de legislación forjado en la Ilustración y asentado durante el Estado liberal de Derecho del siglo XIX y de parte del siglo XX. La ley estatal significó el ocaso del Antiguo Régimen y el comienzo de una etapa de modernización de las instituciones jurídicas, que tiende a establecer una regulación clara y previsible, general y abstracta, y por supuesto a eliminar las diferencias de régimen jurídico dentro de las fronteras de un Estado-nación claramente delimitado. Los filósofos y juristas que impulsaron la empresa codificadora partieron de la convicción de que el presupuesto de los avances en el terreno jurídico, económico y social era una legislación que, aparte de otras virtudes, tuviera un origen exclusivamente estatal y fuera única para el conjunto de sus ciudadanos. En este modelo, la ley estatal se convierte en la fuente del Derecho por excelencia, aunque desde luego su mayor prestigio obedece no sólo a la posesión de las características formales referidas, sino también y sobre todo a la conexión entre democracia y Derecho que esta fuente del Derecho representa: la ley concilia la autonomía de la moral con la heteronomía del Derecho, fundando la producción normativa en la coincidencia entre autores y destinatarios de las normas jurídicas.

En la práctica las leyes no se han ajustado plenamente a esas características que justifican su prestigio, ni siquiera en el Estado liberal decimonónico. De hecho, la idea de “crisis de la ley” o de “crisis del Derecho” no es nueva, sino más bien recurrente en la literatura jurídica contemporánea. Resulta sin embargo paradójico que las características de la unidad, uniformidad y exclusividad del ordenamiento estatal, siendo unas de las más arraigadas y efectivamente caracterizadoras del Derecho de los dos últimos siglos, últimamente son de las más deterioradas. A poco que se observe la realidad jurídica destaca el hecho de que el Estado ha dejado de controlar la producción de buena parte de las normas que disciplinan las relaciones jurídicas de sus ciudadanos. Algunas de estas normas proceden de ordenamientos de ámbito superior al del Estado; otras, de los sistemas jurídicos regionales que tratan

\footnotetext{
Mundial de Filosofía Jurídica y Social, reunido en Granada entre el 24 y el 29 de mayo para analizar los problemas del Derecho y la justicia en una sociedad global.

${ }^{2}$ L. Ferrajoli, ¿Es posible una democracia sin Estado?”, en Razones jurídicas del pacifismo, Edición de G. Pisarello, Trotta, Madrid, 2004, p. 141.
} 
de convivir en armonía con el Derecho estatal ${ }^{3}$, y otras, en fin, tienen por autores a los propios sujetos privados que operan en el mercado.

En efecto, la llamada supraestatalidad normativa supone la creación de Derecho por instancias superiores al Estado, y el ejemplo paradigmático lo representa el Derecho de la Unión Europea, que implica la integración de las leyes de los Estados miembros con un conjunto de normas atípicas, el Derecho comunitario, que, como señala Fernández Tomás, como ordenamiento autónomo, diferenciado e independiente tanto del Derecho internacional como del Derecho interno de los Estados, posee “aplicabilidad directa”, es decir, vigencia automática sin interposición del poder normativo nacional o estatal. En otras palabras, las instituciones comunitarias producen normas sobre las materias transferidas que son directamente fuente de derechos y obligaciones para los ciudadanos ${ }^{4}$. La infraestatalidad normativa, por su parte, supone el reconocimiento de autonomía normativa a entes políticos de ámbito territorial inferior al Estado, lo que da lugar a la convivencia de la ley con fuentes cuyo ámbito de vigencia o aplicabilidad se restringe a un territorio que no coincide con la totalidad del Estado, y a un círculo de destinatarios que, como es lógico, es más reducido que el afectado por el Derecho del Estado. Las leyes de los Länder en Alemania y de las Regioni en Italia, o de las Comunidades Autónomas en España, suponen procesos político-constitucionales de progresivo reconocimiento de las nacionalidades o regiones como entes territoriales que pueden contar con poderes políticos y normativos propios para regular y gestionar las cuestiones que afecten a su territorio y a los residentes en el mismo, velando por sus intereses frente al Estado y frente al resto de las nacionalidades o regiones, y dando lugar a una suerte de potestad legislativa compartida entre las clásicas instancias centrales y los entes políticos territoriales infraestatales ${ }^{5}$.

\footnotetext{
${ }^{3}$ Como señala A. E. Perez Luño, “en las actuales sociedades interdependientes e interconectadas se ha erosionado y en ocasiones se ha llegado a abolir el protagonismo hegemónico y monopolístico de los Estados nacionales en la creación del sistema de fuentes del Derecho”, A. E. Pérez Luño, El desbordamiento de las fuentes del Derecho, Discurso de ingreso en la Real Academia Sevillana de Legislación y Jurisprudencia, Sevilla, 1993, p. 78.

${ }^{4}$ Vid. A. Fernández Tomás, I. Forcada Barona, R. Huesca Vinaixa, A. Sánchez Legido, Instituciones de Derecho Comunitario, $2^{\mathrm{a}}$ ed., Valencia, Tirant Lo Blanch, 2000, pp. 174 y ss. Sin duda, la autonomía del Derecho comunitario plantea problemas desde el punto de vista de su incorporación y eficacia en los sistemas jurídicos nacionales, y a este respecto afirma L. Ferrajoli que el proceso de integración europea ha desplazado fuera de los confines de los Estados nacionales los centros de decisión tradicionalmente reservados a su soberanía, poniendo en crisis la tradicional jerarquía de las fuentes, "El Derecho como sistema de garantías”, en L. Ferrajoli, Derechos y garantías. La ley del más débil, trad. cast. de P. Andrés y A. Greppi, Trotta, Madrid, 1999, p. 17.

${ }^{5}$ R. Jiménez Asensio, La ley autonómica en el sistema constitucional de fuentes del Derecho, Marcial Pons, Madrid, 2001, pp. 28-32.
} 
En resumen, la ley estatal, antaño suprema, exclusiva, y uniforme, se ve abocada en la actualidad a convivir con esas otras fuentes del Derecho, procedentes de organismos públicos de ámbito territorial superior o inferior al del estado, y que por diversos motivos cuentan con legitimidad política ${ }^{6}$. Hasta cierto punto, la pérdida del carácter único del Derecho estatal pondría de manifiesto un proceso inverso al de la construcción del Estado moderno: si éste se guió por el principio de no reconocer poder a ningún tipo de organización distinta (superior o inferior) al Estado, hoy se advierte un cambio en las relaciones políticas en el sentido de que el Estado necesita cooperar con otros Estados o con entes políticos territoriales, y ello se refleja en que cada vez más materias son objeto de competencias normativas concurrentes, cuando no cedidas o sustraídas por completo a la soberanía del Estado.

Pero el retroceso del monopolio estatal de las fuentes del Derecho resulta especialmente erosionado por el creciente protagonismo de las corporaciones y grupos económicos y sociales: los fenómenos de supra- e infraestatalidad normativa, aun cuando implican la revisión de la forma de ejercicio de la soberanía estatal, al menos siguen considerando al Estado un elemento clave de competencias normativas o reguladoras, es decir, no ponen en tela de juicio que las instituciones públicas se hagan cargo de la regulación de los asuntos de interés general. En cambio, el desplazamiento del poder normativo estatal es de otra naturaleza cuando consiste en la influencia o participación legislativa de los grupos portadores de intereses económicos y sociales. La relación entre los poderes públicos y los grupos sociales cambia (o se invierte) respecto del modelo clásico de representación política y de toma de decisiones legislativas y jurisdiccionales del Estado de Derecho: tales grupos confían en la autonomía normativa para la gestión de sus asuntos, más que en las regulaciones uniformes que puedan ofrecer las leyes, y prefieren los mecanismos extrajudiciales de resolución de conflictos de base negociadora, como el arbitraje y la mediación, a las lentas instancias jurisdiccionales. La sociedad, el mercado, los grupos económicos, las corporaciones profesionales, etc., afirman su poder frente al Estado y las tradicionales instituciones político-representativas y administradoras de justicia se resignan a la pérdida de relevancia de la ley como instrumento de regulación. Aunque pueda sonar exagerado, insisto, el panorama presenta alguna semejanza con el Antiguo Régimen: la regulación común y uniforme

\footnotetext{
${ }^{6}$ En este sentido, destaca F. Laporta que la ley "ha llegado a perderse en una selva de normas jurídicas de una fuerza y un ámbito de validez equivalentes al de ella y que, sin embargo, no son producidas por ese órgano legislativo”, "Materiales para una reflexión sobre la racionalidad y crisis de la ley”, Doxa 22 (1999), p. 324.
} 
que propicia la ley se ve poco a poco desplazada por un creciente pluralismo jurídico de origen social.

Ciertamente, la emergencia de grupos económicos y sociales como factor de crisis de la estatalidad del Derecho no es un fenómeno genuinamente nuevo. En realidad el Estado moderno nunca ha logrado evitar manifestaciones de pluralismo jurídico, y los distintos actores sociales nunca han dejado de intentar resolver por sí mismos los asuntos que les afectan y de influir en la producción del Derecho. A principios del siglo XX Santi Romano se expresaba en los siguientes términos? : aparecen "organizaciones y asociaciones, que, a su vez, tienden a unirse y coaligarse entre sí. Éstas se proponen los fines especiales más dispares, aunque todas ellas tienen el carácter común de reagrupar a los individuos con el criterio de su profesión o, mejor, de su interés económico"». Y Klaus Günther, a los efectos de explicar el actual receso de la soberanía estatal en la producción del Derecho, considera indispensables las teorías del pluralismo jurídico, como las tesis de Ehrlich sobre la importancia y vinculatoriedad de la costumbre en paralelo al Derecho positivo del Estado9.

Con todo, y aunque probablemente el pluralismo jurídico nunca haya dejado de existir, lo cierto es que hoy, por diversas circunstancias, algunas de sus manifestaciones se han intensificado. En concreto, parece fuera de toda duda que el repliegue de la ley estatal merced a normas de gestación privada se ha instalado en nuestros sistemas jurídicos: el legislador presta audiencia a grupos organizados que defienden intereses y acepta que influyan en la adopción de decisiones políticas, avala normas en cuya formación el propio legislador apenas ha intervenido ${ }^{10}$, reconoce altas cotas de autonomía nor-

\footnotetext{
${ }^{7}$ S. Romano, "Lo Stato moderno e la sua crisi” (Discorso inaugurale dell' anno accademico 1909-1910), en el libro Lo Stato moderno e la sua crisi. Saggi di diritto costituzionale, Milán, Giuffrè, 1969. Vid. su tesis desarrollada en S. Romano, El ordenamiento jurídico (1919), introducción de S. Martín-Retortillo, Instituto de Estudios políticos, Madrid, 1963.

${ }^{8}$ Romano enumera una serie de organizaciones o asociaciones a las que juzgaba fuente de Derecho en competencia con la ley, y esa enumeración es bastante aproximada a la que haríamos en la actualidad. Así, el autor menciona federaciones o sindicatos de trabajadores, organizaciones patronales, industriales, mercantiles, de agricultores, de funcionarios, sociedades cooperativas, instituciones de mutualidad, cámaras de trabajo, etc., "Lo Stato moderno e la sua crisi”, cit., p. 12.

${ }^{9}$ K. Günther, "Pluralismo jurídico y Código Universal de la Legalidad: la globalización como problema de Teoría del Derecho”, Anuario de Derechos Humanos. Nueva Época. Vol. 4 (2003), pp. 240 y ss.

${ }^{10}$ Uno de los supuestos paradigmáticos de "invasión” del espacio legislativo por los grupos sociales organizados seguramente lo representan los convenios colectivos. A ellos se refiere $\mathrm{N}$. Irti: si en la época del legalismo el valor del contrato se mostraba diciendo que éste "tiene fuerza de ley entre las partes”, en esta nueva era del pluralismo jurídico, en la que determinadas fuentes del Derecho obtienen "energía vinculante, no ya de los poderes constitucionales, sino
} 
mativa a ciertos sujetos privados para la gestión de sus asuntos y, en fin, admite la negociación como vía de solución a sus conflictos.

\section{III) Desregulación y estado social}

El contexto que acaba de describirse de emergencia de grupos integrantes de la sociedad civil, portadores de intereses, sobre todo económicos, y, por consiguiente, de crisis de la soberanía y de la ley estatal, resulta de gran utilidad para explicar la “desregulación”. La expresión denota cierta ambigüedad, pero tal vez convenga señalar que, pese a lo que a primera vista el término pudiera sugerir, no alude a la ausencia de normas, sino a un peculiar estilo de producción normativa, caracterizado por una reducción de normas de carácter público e intervencionista, que contrasta con la relevancia que el propio Estado por diversas vías concede a la autonomía normativa del sector privado $^{11}$. La desregulación no se identifica, empero, con la anomia, sino con la sustitución de una legislación intervencionista, que adopta medidas políticas para influir y modificar las estructuras sociales y económicas, por otra abstencionista, tolerante con las normas procedentes de los propios agentes económicos y sociales, y limitada a garantizar la vigencia de las reglas de juego del libre mercado, en especial la libre competencia o igualdad de oportunidades entre sujetos económicos privados. En este concepto de desregulación tendría cabida, por ejemplo, la derogación de normas estatales que establecen privilegios en favor de entes públicos que compiten en el mercado ${ }^{12}$, aunque no toda manifestación de la desregulación tiene como consecuencia una disminución del volumen de normas, sino que a veces sucede todo lo contrario.

La desregulación, que desde el punto de vista teórico-jurídico puede considerarse una manifestación del pluralismo jurídico, desde el punto de vista filosófico-político suele vincularse al proyecto político neoliberal y a la práctica de privatización de los servicios públicos. La privatización implica un modelo de organización económica inverso al del Estado social, basado en la devolución por parte de los poderes públicos de la producción de bienes y la prestación de servicios a los sujetos privados. La vía para la privatización es justamente la sustitución del régimen jurídico intervencionista e impulsor de lo público por uno abstencionista y "restaurador"

\footnotetext{
del previo acuerdo entre los grandes grupos organizados”, la frase se invertiría diciendo que la ley “tiene fuerza de contrato entre las partes”, La edad de la descodificación, trad. de L. Rojo Ajuria, pres. de A. Luna Serrano, Bosch, Barcelona, 1992, pp. 30-31.

${ }^{11}$ J. R. Capella, Fruta prohibida.Una aproximación histórico-teorética al estudio del derecho y del estado, Trotta, Madrid, 1997, p. 267.

${ }^{12}$ Vid. J. E. Soriano García, Desregulación, privatización y Derecho Administrativo, Publicaciones del Real Colegio de España, Bolonia, 1993, pp. 9-13.
} 
de lo privado, o, lo que es lo mismo, la desregulación ${ }^{13}$. En resumen, la desregulación se asocia a políticas neoliberales, que propugnan la reducción del papel de los poderes públicos en el control de los mercados, mediante una legislación destinada a velar particularmente por la prosperidad de la empresa privada y tendente a reducir lo más posible las obligaciones o responsabilidades empresariales (cargas fiscales, salarios, vacaciones, bajas laborales, protección medioambiental, etc.) $)^{14}$.

Ciertamente junto a esta imagen de la desregulación como instrumento de la privatización y como fórmula legislativa del proyecto político neoliberal, existen otras lecturas de la misma que se resisten a ver en ella una quiebra del Estado social. A modo de ejemplo puede destacarse buena parte de la literatura jurídica administrativista a propósito de la llamada "autorregulación regulada”. Ésta representaría una especie dentro del género “desregulación”, que consiste en la tolerancia por parte de los poderes públicos de las normas gestadas en el ámbito privado, pero con el objetivo de tales normas sirvan para cumplir fines de interés general. Aquí la desregulación no implica tanto el adelgazamiento de las funciones estatales, cuanto una nueva forma, más eficaz, de llevar a cabo las tareas propias del Estado social.

La autorregulación regulada es, en efecto, distinta de la autorregulación a secas: esta última consiste en la ordenación de aspectos básicos del funcionamiento del mercado a través de decisiones que excluyen a los poderes públicos, pues parten de los mismos operadores económicos que actúan en el mercado ${ }^{15}$. En cambio, en el caso de la autorregulación regulada, las

${ }^{13}$ Ibíd., pp. 13-18.

${ }^{14}$ Como resalta J. R. Capella, liberar al empresario de obligaciones en el contrato de trabajo propicia la aparición de muy diversos estatutos laborales, que establecen diferencias por razón de sexo, discriminando a las mujeres; por razón de edad, discriminando a los mayores de 40 años; por razón de nacionalidad, discriminando a los inmigrantes, etc., Fruta prohibida, cit., p. 268.

${ }^{15}$ Vid. S. Muñoz Machado, Tratado de Derecho Administrativo y Derecho Público General, Tomo I, Civitas, Madrid, 2004, p. 1249. J. Esteve Pardo precisa el significado del concepto autorregulación distinguiendo dentro de estas normas que los agentes económicos se dan a si mismos tres categorías: en primer lugar, pautas normativas con cierto grado de abstracción (normas técnicas, protocolos o códigos de conducta); en segundo lugar, acuerdos o decisiones singulares; y en tercer lugar, vías de solución de conflictos, generalmente el arbitraje o la mediación, Autorregulación. Génesis y efectos, Aranzadi, Navarra, 2002, p. 15. M. M. Darnaculleta analiza las materias que suelen ser objeto de autorregulación, y señala que suele tratarse de la disciplina de cuestiones altamente especializadas en lo que respecta al manejo de conocimientos o de técnicas. La autorregulación consiste, pues, en la "actividad privada de producción y control de normas bajo la responsabilidad de quienes las elaboran, aplican o controlan”, y una de sus características fundamentales es que se inspira en la lex artis, esto es, en "las pautas de conducta adecuadas en el quehacer cotidiano de una actividad que requiere la aplicación de ciertos conocimientos científicos, técnicos o éticos, o, cuanto menos, de un cierto grado de especialización”, El Derecho administrativo y la autorregulación: la autorregulación 
autoridades estatales toleran las normas gestadas en el ámbito privado, pero con el objeto de servirse luego de ellas para cumplir fines públicos ${ }^{16}$. Se trata de un método de regulación indirecta: el Estado renuncia a establecer por si mismo el régimen jurídico de algunas materias (especialmente aquellas de elevada complejidad técnica o que plantean importantes problemas éticos), aunque previamente disciplina el contexto en el que ha de tener lugar la actividad normativa de los sujetos privados (contenido mínimo de la regulación o requisitos que debe cumplir, órganos encargados de elaborarlas, los efectos públicos de las mismas), asumiendo los resultados de estos últimos, esto es, los instrumentos de regulación gestados en el ámbito privado, tales como códigos deontológicos, códigos de comportamiento, normas técnicas. Así, la característica que identifica a la autorregulación regulada es la cooperación entre el Estado y los sujetos económicos privados, a fin de cumplir de forma más eficaz y eficiente los intereses generales ${ }^{17}$. Por lo demás, la autorregulación regulada es una técnica normativa frecuente, por ejemplo, en materia financiera, donde a menudo tiene lugar el recurso a los "reglamentos internos de conducta”, que, por cierto, también han cobrado importancia en la regulación de los servicios de la sociedad de la información. Asimismo, en materia de productos industriales y de prevención y control de la contaminación es usual el reenvío a normas de calidad y de técnicas de seguridad ${ }^{18}$.

regulada, publicado en formato electrónico en TDX, Tesis Doctorals en Xarxa, Universidad de Girona, 2003 (www.tdcat.cbuc.es), p. 474 y 417.

${ }^{16}$ Vid. M. M. Darnaculleta Gardella, Derecho Administrativo y autorregulación: la autorregulación regulada, cit.; Esteve Pardo, J., Autorregulación. Génesis y efectos, Aranzadi, Navarra, 2002; J. Cantero Martínez, "La incidencia de la técnica y de las transformaciones sociales en el Derecho Administrativo: el recurso a la llamada autorregulación regulada" (en prensa).

${ }^{17} \mathrm{~J}$. Cantero Martínez, "La incidencia de la técnica y de las transformaciones sociales en el Derecho Administrativo”, cit., p. 35.

${ }^{18}$ En materia de seguridad y calidad industrial, la ley de industria 21/1992, de 16 de julio, permite que sujetos privados realicen funciones públicas de homologación o normalización industrial, certificación y acreditación, vid. sobre este tema J. A. Carrillo Donaire, El Derecho de la seguridad y de la calidad industrial, Marcial Pons, Madrid, 2000, p. 15. En materia financiera, la ley 24/1988, de 28 de julio, del Mercado de Valores (con importantes modificaciones establecidas por la ley 44/2002, de 22 de noviembre, de Medidas de Reforma del Sistema Financiero), supone una apertura a la autorregulación regulada, potenciada desde las instancias comunitarias. Así, el reglamento que desarrolla la ley impone la redacción de códigos de conducta a quienes realicen actividades relacionadas con los mercados de valores. El objeto de tales códigos es elaborar pautas cuyos destinatarios sean los órganos de administración, sus empleados y representantes de las entidades que intervienen en el mercado de valores, a fin de solucionar problemas de comportamiento, velando por el interés de los inversores y el buen funcionamiento y transparencia de los mercados, la buena fe, la imparcialidad, la información clara, correcta, precisa y suficiente a los clientes. El reglamento regula un código general 
La autorregulación regulada se justifica en eficacia no tanto de la economía, cuanto de los propios poderes públicos, y es por ello una de las técnicas de desregulación menos perjudiciales (o que mejor enmascaran) la quiebra del Estado social: asumir los frutos de la autorregulación de los sujetos privados representa un camino para lograr de modo más eficaz y eficiente los propios objetivos del Estado social, paliando el desbordamiento de las autoridades ante la ingente cantidad de tareas que les corresponden en ejercicio de sus funciones ${ }^{19}$, y prueba de ello es la autorregulación regulada predomina en ámbitos, como he señalado, de alta complejidad científica o técnica (industria, sociedad de la información e internet, finanzas, protección del medio ambiente), o que plantean problemas éticos (sanidad).

Desde esta perspectiva de la mayor eficacia o eficiencia de los poderes públicos, la desregulación puede conectarse con la aparición de un nuevo modelo de Estado, el llamado "Estado regulador", que representa una alternativa tanto al Estado garante (liberal) como al Estado gestor/protector (Estado social) $^{20}$. El Estado regulador solventa muchos de los problemas del Estado social, como falta de eficiencia, de fundamento de su paternalismo protector, hiperregulación, elefantiasis de los órganos públicos, multiplicidad incontrolable de demandas sociales, etc., y otros muchos que se agudizan en un contexto de preocupación por la eficiencia de los mercados en un marco económico supranacional. Con las viejas fórmulas de organización estatal, los poderes públicos ni manejan bien los criterios de eficiencia, ni tienen mucho margen de control y de acción, pues se encuentran limitados

de conducta, cuya base son las "Normas de Conducta" surgidas en las reuniones del Comité Técnico de la Organización Internacional de Comisiones de Valores (IOSCO), y si bien la redacción de los códigos de cada entidad es obligatoria, el reglamento permite que puedan ser elaborados por asociaciones profesionales que agrupen a las personas o entidades que intervienen en un concreto ámbito financiero. La CNMV es la encargada de realizar el control de tales reglamentos. Como ejemplo de código de comportamiento puede aludirse al "Código de Buen Gobierno”, código ético para los consejos de administración de las sociedades que negocian en bolsa. Elaborado por una comisión de expertos promovida por la CNMV, es calificado de "ético" y es de carácter voluntario, ya que son las propias entidades las que deciden su aplicación. Otro reglamento (el RD 303/2004, de 20 de febrero, por el que se aprueba el Reglamento de los Comisionados para la Defensa del Cliente de Servicios Financieros) y una orden ministerial (la Orden ECO 734/2004, de 11 de marzo, sobre los Departamentos y Servicios de Atención al Cliente y el Defensor del Cliente de las Entidades Financieras) obligan a que las entidades financieras instituyan unidades de atención al cliente, para la tramitación y resolución de quejas de los particulares.

${ }^{19}$ Vid. J. Martínez Cantero, "La incidencia de la técnica y de las transformaciones sociales en el Derecho Administrativo”, cit., p. 5.

${ }^{20}$ Vid. F. Laporta, “Teoría y realidad de la legislación: una introducción general”, en A. Menéndez Menéndez (Dtor.), La proliferación legislativa: un desafío para el Estado de Derecho, Thomson-Civitas, Madrid, 2004, pp. 44 y ss. Laporta hace referencia aquí al libro de A. La Spina y G. Majone, Lo Stato regolatore, Il Mulino, Bologna, 2000. 
al ámbito nacional, cuando los procesos económicos tienen carácter supranacional. En este panorama surge la alternativa del Estado regulador, que, como señala Laporta, sin ser protagonista de la economía es un actor privilegiado en la articulación de las condiciones de posibilidad del mercado; en la corrección de los fallos del mercado ${ }^{21}$.

Junto a las razones o reivindicaciones de eficacia y eficiencia de los poderes públicos, el discurso de la desregulación suele apelar a razones de legitimidad del Estado ante la sociedad civil ${ }^{22}$. Así se deduce de las palabras de S. Muñoz Machado, para quien el gran hallazgo de formas de desregulación como la autorregulación regulada es que no implica fractura entre el Estado y la sociedad, sino la confluencia entre intereses públicos y privados. El Estado tolera la emergencia de la sociedad civil y su capacidad creadora de normas y la utiliza para el cumplimiento de los fines públicos ${ }^{23}$. En palabras del autor: "el Estado retrocede y abre nuevos espacios a la actuación de las organizaciones de base privada. Lo hace, sin embargo, procurando que esta acción privada sea complementaria y, desde luego, conducida hacia objetivos de interés público, aunque al mismo tiempo satisfagan aspiraciones legítimas relativas al mejor desarrollo de actividades privadas”24. La autorregulación regulada -escribe Darnaculleta Gardella- se convierte en una técnica "que permite a los poderes públicos reequilibrar su poder frente

${ }^{21}$ En palabras de Laporta, el Estado gestor se identifica con "un nuevo tipo de Estado que, sin ser incompatible con la seguridad jurídica que proporciona el Estado garante y sin renunciar a muchas de las dimensiones redistributivas y de integración social del Estado protector, evite sin embargo los obstáculos internos y los frenos burocráticos que caracterizan a este último”, “Teoría y realidad de la legislación”, cit., p. 44. "En términos generales puede decirse que, por comparación con el Estado gestor, el Estado regulador cumple funciones de corrección de fallos del mercado en lugar de funciones de redistribución y estabilización macroeconómica,... renuncia a la dirección ministerial y a las empresas en manos públicas”, Ibíd., p. 45.

${ }^{22}$ Vid. M. M. Darnaculleta Gardella, Derecho Administrativo y autorregulación: la auto rregulación regulada, cit., pp. 531 y ss.

${ }^{23}$ S. Muñoz Machado, Tratado..., cit., p. 1253.

${ }^{24}$ S. Muñoz Machado, Tratado..., cit., p. 1253. En un plano más amplio que el de la actividad normativa de la Administración, P. Salvador Coderch manifiesta una opinión semejante a la de Muñoz Machado, al señalar que la legislación del siglo XXI requiere tomar buena nota de la “teoría económica de la regulación”, entre otras cosas porque ésta contempla la influencia que en la elaboración de las leyes poseen de hecho los grupos de intereses, así como el hecho de que la negociación entre los poderes públicos y los grupos de intereses, y entre los poderes públicos mismos, tiene una importancia crucial en la elaboración de leyes y disposiciones jurídicas de carácter general. A su juicio, la negociación contrarresta el poder coactivo del Estado: la adopción de una decisión en virtud de acuerdos en lugar de por la fuerza de la jerarquía es vista como un modo más legítimo de tomar decisiones públicas, siempre y cuando en tal negociación esté garantizada una suficiente transparencia y se adopten las necesarias cautelas para neutralizar los eventuales conflictos, P. Salvador Coderch, “Técnica legislativa y teorías de la regulación”, en A. Menéndez Menéndez, La proliferación de las leyes: un desafío para el Estado de Derecho, cit., pp. 225-226. 
al creciente poder de la sociedad, legitimar su actuación utilizando los propios argumentos de legitimación de la sociedad y estructurar las relaciones sociales con una intensidad desconocida históricamente”25. Ante argumentos de este tipo, no es de extrañar, por tanto, que otros autores estimen que esta forma de desregulación que supone la autorregulación regulada, más que conectarse con una nueva fase del Estado social, encubre el proyecto político neoliberal que demanda el drástico adelgazamiento de los poderes públicos ${ }^{26}$.

Pero dejando a un lado si determinadas formas de desregulación representan la fórmula más satisfactoria de que hoy disponen los propios poderes públicos para responder a los retos del Estado social en una sociedad cada vez más sofisticada y compleja, o si, por el contrario, se confirman las sospechas que las vinculan con los planteamientos políticos liberales más radicales, lo cierto es que estas manifestaciones de desregulación abren el debate en torno a los riesgos para las garantías ligadas a la democracia y al Estado constitucional de Derecho. Cuando menos, la emergencia de la sociedad civil propicia una legislación concertada o pactada con las instituciones estatales, sin suficientes garantías de participación e igualdad de armas para todos los grupos sociales. Estas formas de legislación "pactada" o "concertada" entre el parlamento y los grupos portadores de intereses económicos, corporaciones profesionales, asociaciones patronales y sindicales, etc., si bien pueden valorarse positivamente por cuanto favorecen una participación más directa y, en consecuencia, amplían "los potenciales de legitimación, cohesión y paz social”, han de ser examinadas con cautela, pues la participación en el concierto legislativo es restringida y desigual, produciéndose el riesgo de subordinación de los intereses generales "bajo presión no fácilmente soportable" a los de "las más fuertes corporaciones, con residuos de democracia casi orgánica”27.

${ }^{25}$ M. M. Darnaculleta Gardella, Derecho Administrativo y autorregulación: la autorregulación regulada, cit., p. 27.

${ }^{26}$ Vid. O. Mir Puigpelat, Globalización, Estado y Derecho. Las transformaciones recientes del Derecho Administrativo, Civitas, Madrid, 2004, pp. 95 y ss.

${ }^{27}$ E. Díaz, "Estado de derecho y legitimidad democrática”, "Estado de Derecho y legitimidad democrática”, en E. Díaz y J. L. Colomer (eds.), Estado, justicia y derechos, Alianza Editorial, Madrid, 2002., p. 93. Una posible solución a este problema podría ser un modelo de legislación que, siguiendo la sugerencia de E. Díaz, completara y equilibrara la influencia de las corporaciones económicas o profesionales con la participación de los nuevos movimientos sociales y de las plurales organizaciones no gubernamentales. Se trataría, en definitiva, de "pasar del corporativismo al cooperativismo, de una exclusiva ética de la competición o de la competencia... a una ética también de la colaboración y la solidaridad”, para lo cual, además, no basta con articular la presencia de la sociedad civil, sino que es imprescindible la acción 
Y la desregulación, aparte de convertir a los agentes económicos en interlocutores privilegiados o directamente en colegisladores, tiene como resultado la delegación de muchas funciones públicas en manos de agencias privadas independientes, que toman decisiones con arreglo a criterios técnicos (al menos en apariencia) de justificación y que son irresponsables política y electoralmente ${ }^{28}$. Y cabe sin duda preguntarse si no se traiciona el principio de legalidad cuando se recurre a normas dictadas por particulares para desarrollar las disposiciones legales, teniendo en cuenta que la remisión a las normas privadas comprende incluso la disciplina de infracciones y sanciones ${ }^{29}$.

En definitiva, pese a lo que la expresión “desregulación” pudiera sugerir, no se identifica con la ausencia de normas -ni siquiera con una disminución del volumen de éstas-, sino con la sustitución de una legislación intervencionista en beneficio de normas de tipo abstencionista, y con la tolerancia o cooperación con la iniciativa normativa privada. La desregulación pone de manifiesto la emergencia de grupos económicos y sociales en la elaboración de las normas, y se une a otros fenómenos de supra- e infraestatalidad normativa, para evidenciar la crisis de la estatalidad del Derecho. Si bien puede considerarse una manifestación de un pluralismo jurídico que seguramente el Estado nunca ha podido realmente neutralizar, cabe señalar que hoy las manifestaciones del pluralismo jurídico en general, y la desregulación en particular, erosionan de modo más intenso el monopolio estatal de las fuentes del Derecho y la soberanía del Estado. La desregulación suele conectarse al proyecto político neoliberal, pero también a nuevas versiones del Estado social que buscan soluciones (como la autorregulación regulada) al desbordamiento de los poderes estatales a la hora de afrontar eficazmente los problemas que acucian a sociedades cada vez más complejas y tecnificadas. La desregulación, como manifestación de la tolerancia del Estado a la creación de normas jurídicas por los particulares, puede valorarse positivamente en la medida en que dota de mayor legitimidad a las decisiones públicas, que toman en cuenta los intereses de los afectados, pero no deja de plantear

de las instituciones político-jurídicas (parlamento, administración, tribunales de justicia, etc.), Ibíd., p. 98.

${ }^{28}$ F. Laporta, “Teoría y realidad de la legislación: una introducción general”, cit., p. 45.

${ }^{29}$ Son reveladoras en este sentido las palabras de Alejandro Nieto, señalando motivos nuevos y distintos de crítica a los poderes públicos: "la Administración Pública, antes tan enérgica, ha terminado rindiéndose ante unos intereses capitalísticos que, para mayor fuerza, superan las barreras nacionales. Y es aquí cabalmente donde está el mayor peligro. La nueva misión del Derecho Administrativo consiste, por tanto, en defender a los ciudadanos y a la Administración de las eventuales (y reales) agresiones de los grupos privados, mucho más poderosos que las propias Administraciones”, A. Nieto, “Recensión al libro de J. Esteve Pardo, Autorregulación. Génesis y efectos”, Revista de Administración Pública, 160 (2003), p. 429. 
interrogantes y problemas desde el punto de vista de la representación de todos los intereses en condiciones de igualdad.

\section{IV) La desregulación como técnica normativa paradigmática de la sociedad global}

Hasta aquí se ha tratado de mostrar que la desregulación puede considerarse una manifestación de pluralismo jurídico estatal, cuyo caldo de cultivo es la relevancia que los grupos portadores de intereses, sobre todo económicos, cobran en la creación del Derecho. Pues bien, desde esta perspectiva, esta forma peculiar de dar origen a normas adquiere un lugar destacado a la hora de analizar las transformaciones del Derecho en la globalización ${ }^{30}$. En particular, la desregulación adquiere importancia como modo de producción del Derecho, en la medida en que la globalización pudiera caracterizarse por la afirmación del poder de sujetos del mundo financiero y empresarial frente al poder del Estado. Así, L. Ferrajoli menciona la desregulación o, en sus propias palabras, el vacío de Derecho público, como la principal manifestación de la globalización en el plano jurídico internacional.

“El principal efecto de la crisis del Estado en el plano internacional ha sido la producción de un vacío de derecho público. Esto es, la ausencia de reglas, de límites y vínculos que garanticen la paz y los derechos humanos frente a los nuevos poderes transnacionales, públicos y privadas, que han depuesto a los viejos poderes estatales o que, en todo caso, han conseguido liberarse de sus funciones de gobierno y de control. Pienso incluso que la propia globalización de la economía puede ser identificada, en el plano jurídico, con este vacío de un derecho público internacional capaz de disciplinar los grandes poderes económicos transnacionales. Obsérvese que no se trata de un vacío de derecho, que no puede existir nunca, sino de un vacío de derecho público que inevitablemente ha sido colmado por un plexo normativo de derecho privado, es decir, por un derecho de producción contractual que ha pasado a sustituir a las fuentes jurídicas tradicionales y que refleja, con frecuencia, la ley del más fuerte”, L. Ferrajoli, “¿Es posible una democracia sin Estado?”, cit., p. 142 (cursiva añadida).

Excede las posibilidades de este trabajo analizar y confrontar las distintas tesis sobre la globalización o mundialización. Por ello, aquí fundamentalmente se usará una cierta concepción de los cambios que ha producido la globalización -la que, entre otros, sostienen D. Held y A. Macgrew- a los efectos de dar cuenta de ciertos factores que, en efecto, hacen de la des-

\footnotetext{
${ }^{30}$ Así, W. Twining insiste en tener en común con B. S. Santos que ambos tratan las manifestaciones del pluralismo jurídico como fenómenos centrales del Derecho, sobre todo si éste se considera desde una perspectiva global, W. Twining, Derecho y Globalización, Est. Prelim. De O. Guardiola-Rivera y C. Sandoval, Bogotá, Universidad de Los Andes-Facultad de Derecho, 2003, pp. 211-291.
} 
regulación el modo de creación del Derecho paradigmático en la sociedad global $^{31}$.

Un significado extendido del término globalización es la "tendencia de los mercados y de las empresas a extenderse, alcanzando una dimensión mundial que sobrepasa las fronteras nacionales”32. Sin lugar a dudas, es en el ámbito económico donde se producen con mayor intensidad procesos globales: la economía opera como "la fuerza impulsora de la globalización contemporánea, y no se puede realizar una conceptualización respecto de la naturaleza y modelo de globalización sin hacer referencia a este aspecto”33. Sin embargo, parece aconsejable examinar la globalización desde una perspectiva más amplia que la económica, en la línea de D. Held y A. Macgrew $^{34}$. Desde esta óptica, la globalización se identifica con cambios significativos, profundos o estructurales en la escala o ámbito de las relaciones sociales, económicas, políticas, así como en sus principios organizativos. Las manifestaciones más importantes de la globalización serían, a juicio de los autores citados, el crecimiento de las corporaciones multinacionales, los mercados financieros mundiales, la difusión de las culturas y la importancia de la degradación medioambiental global. En definitiva, la globalización representa un fenómeno esencialmente económico, aunque sostenido en varios pilares, de tipo ideológico (filosofía liberal o neoliberal), político (difuminación de las fronteras estatales y debilitamiento del Estado como monopolizador del poder dentro de las mismas), tecnológico (el espectacular desarrollo de las nuevas tecnologías de la información y comunicación, y en especial de la red ${ }^{35}$ ), y jurídico (el surgimiento de normas transnacionales

${ }^{31}$ A este respecto, indica M. Atienza que la globalización se vincula a la ideología neoliberal, a la privatización y a la tendencia jurídica a la desregulación, El sentido del Derecho, Barcelona, Ariel, 2001, p. 127-129.

${ }^{32}$ Esta es la definición que aparece en la última edición del Diccionario de la Real Academia Española.

${ }^{33}$ D. Held y A. Mcgrew, “Globalización: tendencias y opciones”, La globalización económica. Incidencia en las relaciones sociales y económicas, Consejo General del Poder Judicial, Madrid, 2002, p. 158.

${ }^{34}$ D. Held y A. Mcgrew, Globalización/Antiglobalización. Sobre la reconstrucción del orden mundial (2002), Paidós, Barcelona, Buenos Aires, México, 2003, pp. 13 y ss.

${ }^{35}$ Precisamente la regulación de la red o, más exactamente, de las actividades que tienen lugar a través de la misma (prestación de bienes y servicios, suministro de información, transmisión de datos, etc.), representa, en opinión de algunos, el campo paradigmático de uso de la técnica normativa desreguladora: la red es un instrumento que nació libre y en esa libertad ha encontrado y encuentra su formidable desarrollo, de modo que "la reglamentación debe limitarse a lo estrictamente necesario para conseguir unos objetivos definidos y un marco claro y previsible, que dé seguridad a los operadores y usuarios”, S. Muñoz Machado, La regulación de la red. Poder y Derecho en internet, Taurus, Madrid, 2000, p. 54. 
y en buena medida elaboradas por los propios sujetos privados que operan en el mercado global).

Frente a lo que sostienen algunos autores, el discurso de la globalización ni exagera la trascendencia y la novedad de los cambios, ni resulta conveniente presentarlo como un mero discurso ideológico al servicio del capitalismo occidental. En efecto, por un lado, la globalización entraña procesos distintos a los de internacionalización y regionalización: se manifiesta en relaciones que se desarrollan y organizan más allá del ámbito de las fronteras o del territorio de un país, pero no se trata de un aumento o una mayor intensidad en las relaciones interestatales, ni tampoco de un crecimiento de los procesos de agrupación de Estados contiguos geográficamente, porque la globalización entre otras cosas desafía el propio principio de organización de las relaciones políticas, económicas y sociales en el que se basan tales fenómenos de internacionalización y regionalización, a saber, el Estado nacional. Por otro lado, reducir la globalización a un nuevo estadio del capitalismo parece simplificador en exceso, porque realmente se están produciendo una serie de cambios en la escala o dimensión de las relaciones sociales, por más que a menudo el discurso globalizador pueda estar al servicio de fuerzas económicas, políticas y sociales muy poderosas de occidente. En otros términos, si efectivamente están produciéndose cambios cualitativos en las relaciones económicas, sociales y políticas, entonces resulta preciso interrogarse a modo de reto o desafío por nuevos principios organizativos idóneos para afrontar las transformaciones del siglo XXI con garantías semejantes a las que ofrecía el modelo del Estado de Derecho, y ello sin perjuicio de que al mismo tiempo se pueda levantar acta o criticar los beneficios que determinadas fuerzas económicas y sociales obtienen de la globalización o de ciertos discursos a propósito de la misma ${ }^{36}$.

Resumiendo, la globalización, que representa un cambio efectivo, significativo o profundo en la escala de la interacción social, y que tiene como fuerza impulsora los procesos globales en el ámbito de la economía, desafía al Estado como clave de la organización de las relaciones políticas, y por consiguiente, erosiona el monopolio estatal de la creación y de la aplicación del Derecho. La globalización plantea por ello la necesidad de reflexionar sobre las transformaciones del modelo de Estado y de Derecho que demanda la sociedad global.

Pues bien, precisamente una de las propuestas de transformación del modelo de Estado y de Derecho es, en palabras de K. Günther, la “sociedad

${ }^{36}$ D. Held y A. Mcgrew, Globalización/Antiglobalización, cit., pp. 17 y ss. 
global de Derecho privado"37, y de facto la desregulación puede considerarse una manifestación de esa propuesta. La desregulación, que en línea de principio se conecta a la crisis del Estado social por la emergencia de los sujetos económicos privados, se consolida como técnica productora de normas predilecta en la sociedad global ${ }^{38}$. Y resulta comprensible que esto suceda, en la medida en que la globalización propicia, como se desarrolla a continuación, que los agentes económicos privados que operan a escala mundial logren hacerse impermeables o escurridizos a las legislaciones estatales, se rijan por normas creadas por ellos mismos sobre la base de negociaciones, y que crezca su influencia e importancia sobre los poderes públicos de los Estados. El resultado es la proliferación de normas privadas y sistemas de resolución de conflictos al margen de las instancias públicas, de legislaciones estatales tendentes a eliminar en la mayor medida posible barreras u obstáculos que perjudiquen la libertad y la prosperidad de los sujetos económicos; legislaciones estatales deferentes hacia las normas gestadas en el ámbito privado (incluso haciendo uso de ellas para la obtención de fines de interés general) y sensibles a sus intereses otorgando a empresas o bancos el estatuto de actores en procesos de negociación ${ }^{39}$.

\footnotetext{
${ }^{37}$ Con todo, K. Günther se apresura a señalar que este modelo político y jurídico tiene que luchar "con los problemas de una totalización de la economía, con la cuestionabilidad de la teoría económica que supuestamente se aplica a sí misma, privada de crítica política, así como con las crisis económicas reales de la globalización", "Pluralismo jurídico y Código Universal de la Legalidad", cit., p. 256. Por ello, frente a este y también frente a otros modelos propuestos, Günther, siguiendo a Habermas, postula un Código Universal de la Legalidad: el Código Jurídico, contingentemente institucionalizado en la forma de Estado nacional democrática, tiene que dar paso a un Código Universal de la Legalidad en el curso de la globalización, en el que las determinaciones y fijaciones concretas son "negociadas" por los participantes, Ibíd., pp. 250-252.

${ }^{38}$ La desregulación es vista por C. Berzosa Alonso-Martínez como uno de los principales instrumentos del proyecto neoliberal y neocapitalista que supone la globalización: la globalización, escribe el autor, "es un proceso en el que se pretende eliminar las barreras físicas y reglamentarias, que entorpezcan la libre circulación de mercancías y de capitales, y de todo lo que suponga alguna traba para la reproducción del capital". Los "tres principales factores de impulso son la liberalización, privatización y desregulación”, "Los efectos negativos de la globalización y propuestas alternativas”, La globalización económica. Incidencia en las relaciones sociales y económicas, Consejo General del Poder Judicial, Madrid, 2002, p. 134.

${ }^{39}$ Así, para D. Held y A. Mcgrew, una de las manifestaciones más evidentes de la globalización política es la "creciente involucración de instituciones públicas y privadas en la elaboración de normas”. Siguiendo a Teubner, señalan que en diversos sectores del orden global, han surgido foros de elaboración de normas, la mayoría nacidos para la "estandarización técnica, la elaboración de normas profesionales, la regulación interna de las multinacionales, y, a través de la contratación mercantil, el arbitraje y otros elementos de la lex mercatoria". "La combinación de actores públicos y privados -prosiguen los autores- está reconfigurando la base a partir de la que se están elaborando normas y sistemas normativos... Ya no existe una separación rigurosa entre trámites y mecanismos legales públicos y privados, nacionales e internacionales, y
} 
Las repercusiones jurídicas de los cambios institucionales producidos por la globalización han sido analizadas por J. R. Capella, y en particular este autor conecta la desregulación jurídica con tres características de los agentes económicos que protagonizan procesos globales: $a$ ) su carácter transnacional, $b$ ) su necesidad de encontrar un marco normativo operativo y uniforme, y c) su creciente capacidad de presión sobre los gobiernos ${ }^{40}$.

a) Comenzando por el carácter transnacional de los agentes económicos que protagonizan procesos globales, Capella señala que la "mundialización" ha afectado al Estado, convirtiéndolo en permeable, abierto o subalterno a las influencias de un soberano de carácter "privado", "supraestatal" y "difuso". Este poder metaestatal se encuentra en el conjunto de empresas transnacionales y en los conglomerados financieros. Por eso, desde el punto de vista de la legislación estatal, la crisis de la soberanía del Estado se manifiesta en su escasa o nula influencia a la hora de disciplinar las actuaciones de agentes económicos de ámbito superior al nacional. En efecto, las empresas y operadores financieros de carácter transnacional escamotean fácilmente las normas estatales. Se afincan en paraísos fiscales para evadir impuestos y trasladan la fase de elaboración de sus productos a aquellos países en los que no se sanciona eficazmente ni el trabajo infantil, ni las largas jornadas e indignas condiciones de trabajo, ni la contaminación ${ }^{41}$. En realidad, la existencia de paraísos normativos se explica porque los Estados se ven obligados a competir entre sí por medio de regulaciones que favorecen las inversiones y actuaciones económicas en su territorio, a base de legislaciones liberalizadoras, bajando los impuestos que gravan a las empresas y flexibilizando las normas sociales; en suma, sustituyendo normas de tipo intervencionista y asistencial por normas inspiradas en el laissez faire. En otras palabras, la desregulación es una respuesta de los Estados nacionales al forum shopping, o búsqueda del ordenamiento más favorable por parte de las empresas multinacionales ${ }^{42}$.

b) En segundo lugar, Capella destaca otra circunstancia que propicia la desregulación en la sociedad global, a saber: los agentes económicos necesi-

los modelos de legislación y aplicación de la ley ya no se ajustan con facilidad a la jerarquía unificada de los sistemas de Estado", D. Held y A. Mcgrew, "Globalización: tendencias y opciones”, La globalización económica. Incidencia en las relaciones sociales y económicas, Consejo General del Poder Judicial, Madrid, 2002, p. 173

40 J. R. Capella, Fruta prohibida, cit., pp. 260 y ss.

${ }^{41}$ C. Berzosa Alonso-Martínez, "Los efectos negativos de la globalización y propuestas alternativas”, La globalización económica. Incidencia en las relaciones sociales y económicas, Consejo General del Poder Judicial, Madrid, 2002,pp. 141-143

${ }^{42}$ Vid. K. Günther, "Pluralismo jurídico y Código Universal de la Legalidad: la globalización como problema de Teoría del Derecho”, cit., p.231. 
tan un marco normativo uniforme a escala global. En efecto, que los sujetos económicos escapen a las normas estatales y al mismo tiempo coarten a los Estados en contra de barreras normativas a su prosperidad no significa que puedan prescindir de marcos normativos (ni de mecanismos de resolución de conflictos), pero sí que predomine la iniciativa privada. Los propios sujetos económicos estiman que son quienes mejor conocen sus necesidades e intereses, de modo que no confían dicha tarea al Estado, sino que optan por la autonormación. Una de las manifestaciones más claras de esta forma de desregulación es la nueva lex mercatoria, que ha sido vista como una fuente de Derecho independiente de cualquier poder público y basada en un proceso de negociación en el que participan agentes económicos transnacionales. La nueva lex mercatoria, integrada por usos y prácticas (contratos-tipo, reglas de asociaciones privadas, etc.) altamente frecuentes en las transacciones comerciales internacionales, es, en efecto, considerada por muchos autores como verdadero ordenamiento jurídico: se trata de normas, cuyos autores no son los Estados sino los operadores del comercio internacional, es decir, la Societas Mercatorum, el llamado "círculo de comerciantes más poderosos” o las Big Corporations del siglo XXI ${ }^{43}$.

Con independencia de que esta nueva lex mercatoria pueda calificarse o no de ordenamiento autónomo, lo cierto es, como resalta Capella, que sus normas se orientan a la expansión de la organización económica capitalista, así como a la desaparición de fronteras en lo que a los flujos financieros o al mercado de todo tipo de bienes y servicios respecta. Versa, pues, exclusivamente, sobre intereses empresariales, siendo su contenido acuerdos empresariales de producción, normalización, distribución de mercados, resolución

${ }^{43}$ La nueva lex mercatoria es considerada un ordenamiento jurídico autónomo por S.M. Carbone, U. Draetta, F.K. Juenger, A. F. Lowenfeld, vid. A. L. Calvo Caravaca, y Javier Carrascosa González, Derecho Internacional Privado, vol. II, Comares, Granada, 2004, pp 502 y ss. Con todo, la doctrina no es unánime a este respecto, y de hecho una extendida acepción de la nueva lex mercatoria es aquella que la caracteriza como un conjunto de usos y prácticas que, junto con el Derecho estatal, regulan algunos aspectos de la contratación internacional. A favor de esta acepción se argumenta que los tribunales estatales consideran que la lex mercatoria regula aquellos aspectos en los que las partes están de acuerdo, teniendo el valor de un pacto privado interpartes, pero siempre hay una ley estatal reguladora del contrato, y en particular se argumenta que el sistema sancionador de la lex mercatoria es débil y poco efectivo; es decir, la nueva lex mercatoria, aun teniendo muchos rasgos que permitirían calificarla de ordenamiento jurídico autónomo, carece de la coercitividad, como rasgo definitorio de la juridicidad, ibíd. En un sentido semejante, F. J. Laporta considera que la nueva lex mercatoria es valorada como un buen instrumento de coordinación y cooperación, y rebaja los costes de transacción al dar fijeza a las condiciones de la misma, pero tiene poca virtualidad a la hora de resolver conflictos, Ponencia plenaria titulada "Globalización e imperio de la ley. Un texto provisional para el debate con algunas dudas y perplejidades de un viejo westfaliano”, presentada en el XXII Congreso Mundial de Filosofía del Derecho y Filosofía Social, Granada, 2005 Anales de la Cátedra Francisco Suarez (en prensa). 
extrajurisdiccional de conflictos, etc. ${ }^{44}$. Por lo demás, otra prueba de que la nueva lex mercatoria es un ejemplo de desregulación, y de que ésta no se identifica con el vacío normativo, sino con una forma de producción de normas dominada por sujetos privados, es que muchas de sus normas han sido ya codificadas usando sofisticadas técnicas legislativas que tienden a la uniformización de las reglas de juego del mercado a nivel global o mundial ${ }^{45}$.

c) La tercera y última circunstancia que explicaría que una de las transformaciones jurídicas más importantes operadas por la mundialización sea la desregulación es, siguiendo a Capella, que los agentes económicos a escala global poseen una alta capacidad de presión e influencia sobre los poderes públicos estatales. La importancia que en el “adelgazamiento” del Derecho han pasado a tener los agentes económicos de ámbito transnacional no sólo es patente en el control prácticamente exclusivo que éstos ejercen en sus relaciones jurídico-privadas, sino también en su influencia en políticas de desregulación dentro de los Estados. Es decir, la iniciativa normativa privada no se limita a la disciplina de sus propios asuntos, sino que se proyecta en la capacidad de negociar y de influir sobre los poderes públicos, bien a través de instituciones interestatales, como el G8, el Banco Mundial, el Fondo Monetario Internacional, la Organización Mundial del Comercio, etc. ${ }^{46}$, bien en el seno de las instituciones estatales, por medio de lobbies que pactan con los gobiernos y con los partidos políticos. Sin lugar a dudas, el legislador necesita tomar en consideración cada vez más a la empresa transnacional a la hora de diseñar las políticas públicas ${ }^{47}$, porque la fuerza de ésta aumenta en virtud de procesos de concentración y fusión.

En suma, la globalización ha inaugurado un nuevo estadio en las relaciones poder-Derecho caracterizado por el retroceso, probablemente irrever-

${ }^{44}$ J. R. Capella, Fruta prohibida, cit., pp. 272-277.

${ }^{45} \mathrm{Y}$ así se pone de manifiesto en los INCOTERMS 2000 o cláusulas uniformes en la contratación internacional, en las Reglas Uniformes CCI para Créditos Documentarios, en las Reglas Uniformes sobre Cobranzas de Documentos, todas ellas dispuestas por una institución totalmente privada, que es la Cámara de Comercio Internacional, Vid. A. L. Calvo Caravaca, Derecho Internacional Privado, cit., pp 502-510.

${ }^{46}$ J. R. Capella, Fruta prohibida, cit., p. 261. A juicio de Ferroli el poder de estas instituciones que representan intereses estrictamente privados no encuentra ningún contrapeso en las instituciones del orden internacional, ni siquiera la ONU, que padece una involución respecto del momento en que fueron creadas, como se pone de manifiesto en el sistemático incumplimento de sus resoluciones. En efecto, el Derecho público internacional se encuentra en situación de vacío. Falta una esfera pública mundial a la altura de los grupos de intereses organizados como el G8, FMI, BM, OMC, o las empresas transnacionales y los conglomerados financieros. El Derecho internacional es hoy un conjunto de promesas incumplidas, L. Ferrajoli, “¿Es posible una democracia sin Estado?”, cit., pp. 141-144.

${ }^{47}$ Vid. D. Held, La democracia y el orden global. Del Estado moderno al gobierno cosmopolita (1995), trad. de S. Mazzuca, Paidós, Barcelona, 1997, p. 38 y pp. 129 y ss. 
sible, del Estado, que a pasos agigantados está dejando de ser la instancia fundamental en la dirección de la actividad económica, la producción y la aplicación de las normas. En el plano jurídico, una de las consecuencias más importantes es la desregulación, bajo formas de legislación en las que predomina la iniciativa normativa de los sujetos económicos, especialmente de aquellos que operan a escala global ${ }^{48}$ : desarrollo de políticas abstencionistas, deferencia estatal hacia la autonormación, delegación en sujetos y normas privadas del ejercicio de funciones públicas, receptividad y sensibilidad de los poderes públicos a los intereses y presiones de los agentes económicos globales, etc. La desregulación se aproxima, en fin, al vacío de Derecho, pero no de todo Derecho, sino de un Derecho público (nacional o internacional) destinado a garantizar intereses generales ${ }^{49}$.

Al comienzo de este trabajo se hacía referencia a la pretensión de influir en la creación de Derecho de los grupos económicos y sociales o de la sociedad civil como manifestación del pluralismo jurídico dentro del Estado, que, si bien seguramente siempre ha existido, en la actualidad se ha acentuado hasta el punto de tratarse de uno de los factores que más erosionan la

${ }^{48}$ Podría objetarse a esta definición de “desregulación” que es demasiado amplia o que contempla demasiados fenómenos: no sólo aquellos en los que tiene lugar la sustitución de una previa legislación estatal intervencionista por otra liberalizadora, sino también aquellos otros que reflejan la directa creación de normas por los sujetos privados al margen de los Estados (piénsese de nuevo en la lex mercatoria). Estas últimas manifestaciones encajarían tal vez mejor en el concepto de autoformación, autorregulación o "autonomización global del sistema económico” (Vid. los fenómenos que K. Günther adscribe a este concepto, "Pluralismo jurídico y Código Universal de la Legalidad”, cit., p. 232). Sin embargo, creo que es preferible incluir estos supuestos en la expresión desregulación, al menos por dos razones. En primer lugar, porque a pesar de que estos fenómenos muestran la autonomía de los actores económicos globales, el Estado sigue siendo un actor prominente, en la medida en que la ejecución de las pretensiones jurídicas sigue siendo llevada a cabo por el Derecho estatal; es decir, porque el Estado continúa teniendo el monopolio de la fuerza. Y, en segundo lugar, quizás sea preferible hablar de desregulación como modo de toma de postura en contra de propuestas de gobierno mundial basadas en el imperio del Derecho privado: si la desregulación no propende a la ausencia de normas, sino la sustitución de éstas por normas con un origen privado o, lo que es igual, al adelgazamiento o vacío de Derecho público, nacional o internacional, hablar de desregulación implica una propuesta normativa, en el sentido de que, cualesquiera que sean las transformaciones que la globalización implique para el Derecho, siempre será necesaria una "regulación de carácter público” que se ocupe de los asuntos de interés general. En otras palabras, el término “desregulación” puede emplearse en sentido crítico, para objetar la autorregulación de sujetos privados, la negociación y el arbitraje fuera de instancias jurisdiccionales descentralizadas como medio de solución de los problemas de interés general.

${ }^{49}$ Señala M. Atienza que "la desregulación no significa acabar con el poder, sino sustituir un poder (el poder del Estado) por otro poder, el que cada parte tiene en un proceso de negociación; la desregulación suele tener por ello consecuencias favorables para los que están en una situación de mayor poder económico, que pueden ejercerlo sin tener que someterse a las normas estatales”, M. Atienza, El sentido del Derecho, El sentido del Derecho, Ariel, Barcelona, 2001, pp. 133-134. 
estatalidad del Derecho. Asimismo, se aludía al hecho de que esa situación propiciaba, cuando menos, una legislación concertada o pactada con las instituciones estatales, sin suficientes garantías de participación e igualdad de armas para todos los grupos sociales. Pues bien, en el marco de la globalización económica, los riesgos potenciales para la democracia, e incluso para las garantías más básicas (paz, seguridad y respeto de los derechos fundamentales) se multiplican: la ley estatal desaparece en medio de las presiones de agentes económicos transnacionales más compactos y sobre todo incomparablemente más fuertes que las corporaciones empresariales y profesionales de ámbito nacional ${ }^{50}$.

Alertar así de los riesgos de la desregulación como una de las formas predilectas de legislación en la sociedad global no implica incurrir en la falacia de la pendiente resbaladiza: la desregulación puede esgrimir en su favor los principios del liberalismo económico, pero plantea problemas desde el punto de vista de la democracia, entre otras cosas porque no parece fácil discernir las cuestiones que carecen de trascendencia pública (y que podrían, por tanto, quedar al margen de los procedimientos de decisión democráticos, es decir, al libre concierto de los sujetos privados) de las que, por el contrario, harían preceptiva la regulación "legal”, es decir, por una instancia legitimada y encargada de tutelar los intereses públicos. Dicho de otro modo, la desregulación pone de manifiesto que el auge de una de las propuestas de transformación del Derecho en la sociedad global es la sociedad global de Derecho privado. Sin duda, se halla lejos de ser la única propuesta ${ }^{51}$, pero

${ }^{50} \mathrm{~S}$. Holmes señala que la consecuencia de la crisis de la soberanía estatal es una situación de pluralismo estatal débil o pluralismo desregulado: “cuando el Estado, la única institución social disponible que puede defender sistemáticamente los intereses de los débiles, se "privatiza”, cuando se convierte totalmente, y no parcialmente, en la herramienta de los fuertes, entonces no pueden surgir relaciones liberales entre el Estado y la sociedad [...] Mientras que un gobierno débil -continua el mismo autor- toma las demandas secuencialmente y cede frente a la presión por subsidios hasta que la caja registradora se vacía, un gobierno fuerte reúne todas las demanda, identifica cuáles son las más importantes y entrega un paquete para satisfacer, al menos en parte, a los solicitantes más indicados" "El constitucionalismo, la democracia y la desintegración del Estado”, en H. Hongju Koh y R. C. Slye (comp.), Democracia deliberativa y derechos humanos, trad. De P. Bergallo y M. Alegre, Gedisa, Barcelona, 2004, p. 145 y p. 149.

${ }^{51}$ En efecto, la mayor parte de las propuestas giran en torno a la viabilidad de la democracia en la sociedad global, tal y como se encuentra articulada en los actuales Estados nacionales, así como sobre las posibles adaptaciones del modelo en aras de su aplicación a un orden político global. Muy brevemente, cabría identificar a este respecto tres orientaciones: la primera sería la llamada democracia construida “desde abajo”, esto es, la democratización global basada en la participación en la toma de decisiones públicas en virtud del asociacionismo (Vid. M. Kaldor, La sociedad civil global, trad. de D. Udina, Tusquets, Barcelona, 2005); la segunda orientación sería la de la democracia construida “desde arriba”, que significaría el paso al cosmopolitismo político (Vid. J. Habermas, La constelación posnacional, Paidos, Barcelona, 2000), mediante un orden político y jurídico global que extienda el modelo del constitucionalismo (Vid. L. 
de facto tiene quizás mayor implantación que otras. Quizás por ello, Danilo Zolo, al hilo de su discusión sobre la alternativa entre un modelo "globalista de maxima civitas" y un paradigma "neowestfaliano", y tras apostar por este último, es decir, por la revalorización del papel del Estado, y por el carácter irrenunciable de un orden internacional que se siga basando en el pluralismo de Estados soberanos ${ }^{52}$, resalta que su propuesta se opone doblemente a la propuesta de los globalistas, y también a las teorías “-por ejemplo las tesis de Kenichi Ohmae- que en nombre de la soberanía planetaria del mercado propone una desregulación política global”³3.

En fin, y para concluir, la desregulación pone de manifiesto que la crisis del Derecho legal es hoy efecto de concepciones negatorias o críticas en principio del Estado social, pero en el fondo del propio Estado. Puede parecer paradójico, pero si la irrupción del Estado social propició una cierta crisis de la ley, la propia crisis del Estado social anuncia, a su vez, nuevos motivos de preocupación para los valores que siempre han estado detrás de la forma legal ${ }^{54}$. La globalización de los mercados, aun cuando invoque los principios del liberalismo económico, desafía al Estado y a este instrumento liberal por excelencia que fue la ley ${ }^{55}$. Precisamente por ello, y dado que la actitud pasiva ante la crisis de la legalidad conduce a respuestas como la desregulación (con el grave riesgo que ello supone no sólo para la represen-

Ferrajoli, L. Ferrajoli, Razones jurídicas del pacifismo, cit.). A grandes rasgos, el cosmopolitismo político se basaría en los siguientes principios: a) vigencia de una estructura normativa que enuncie los principios de la ética democrática y que vincule a los diferentes dominios o poderes políticos, sociales y económicos; $b$ ) reforma de los organismos internacionales, sustituyendo progresivamente la representación de los Estados por representantes de pueblos e individuos; $c$ ) reforma de las instancias jurisdiccionales internacionales, que hicieran cumplir efectivamente las normas del orden cosmopolita; la tercera orientación sería la que podría llamarse "neowestfaliana”, que postula el mantenimiento del protagonismo del Estado, que canalizaría las demandas de sus ciudadanos con repercusión global. Se trataría de un Estado con perspectiva "cosmopolita” en lo que a la visión de los problemas se refiere, y guiado en sus relaciones con otros Estados y agentes sociales globales por el principio de tolerancia (Vid. D. Zolo, Cosmópolis. Perspectivas y riesgos de un gobierno mundial (1997), Trad. de R. Grasa y Francesc Serra, Paidós, Barcelona, 2000; U. Beck, Poder y contrapoder en la era global, trad. de R. S. Carbó, Paidós, Barcelona, 2004; D. Held, La democracia y el orden global, cit.). Esta suerte de "tercera vía” argumenta a su favor tratarse de una propuesta más pragmática que las dos primeras orientaciones, que siendo plausibles desde un punto de vista filosófico, plantean dificultades de naturaleza práctica o institucional.

${ }^{52}$ En el mismo sentido, vid. F. Laporta, “Globalización e imperio de la ley”, cit.

${ }^{53}$ D. Zolo, Cosmópolis, cit., pp. 13-17 y pp. 137-177, y en especial p. 14.

${ }^{54}$ Vid. G. Marcilla, Racionalidad legislativa. Crisis de la ley y nueva ciencia de la legislación, Pról. de M. Gascón, Madrid, CEPC, 2005, pp. 174-202.

${ }^{55}$ L. Ferrajoli, Derecho y razón, Teoría del garantismo penal (1989), trad. de P. Andrés Ibáñez, A. Ruiz Miguel, J. C. Bayón Mohino, J. Terradillos Basoco, R. Cantarero Bandrés,

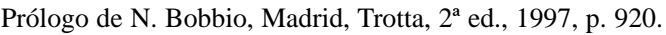


tación de los intereses de los menos fuertes, y la garantía de los derechos fundamentales, sino incluso para la propia paz y seguridad mundial) quizás tenga razón L. Ferrajoli al afirmar que ha llegado el tiempo de emprender una nueva ciencia de la legislación ${ }^{56}$.

\footnotetext{
${ }^{56}$ A su juicio, "sólo un relanzamiento del papel de la ley, sostenido por una renovada y actualizada ciencia de la legislación, puede restaurar y en muchos instaurar una legalidad garantista, anclándola sólidamente en la tutela de los derechos fundamentales”, L. Ferrajoli, Derecho y razón, cit., p. 920. Las transformaciones que ha supuesto la globalización han alterado las condiciones de la posibilidad de la democracia (modelo político) y del Estado de Derecho (modelo jurídico), ya que tales condiciones de posibilidad hoy no pueden estar tuteladas por una esfera pública estatal, sino una de dimensión mundial y global. Urgen, pues, instituciones y funciones capaces de tutelar intereses generales, a la altura de los nuevos actores políticos transnacionales, públicos y privados. Ciertamente, buena parte de la filosofía política y jurídica califica la extensión del constitucionalismo al orden internacional de propuesta utópica y poco realista. Ferrajoli replica que esta objeción es falaz: los obstáculos a su propuesta provienen de intereses políticos contrarios: ¿por qué es una utopía el cumplimiento de las resoluciones de la ONU o la operatividad del Tribunal Penal Internacional?. Es una cuestión de voluntad, que sobre todo afecta a EEUU, pues bastaría que renunciara a ser la potencia militar, económica y política del mundo, “¿Es posible una democracia sin Estado?”, en Razones jurídicas del pacifismo, Edición de G. Pisarello, Trotta, Madrid, 2004, pp. 149-150.
} 
$\triangle \quad$ DOXA 28 (2005) 